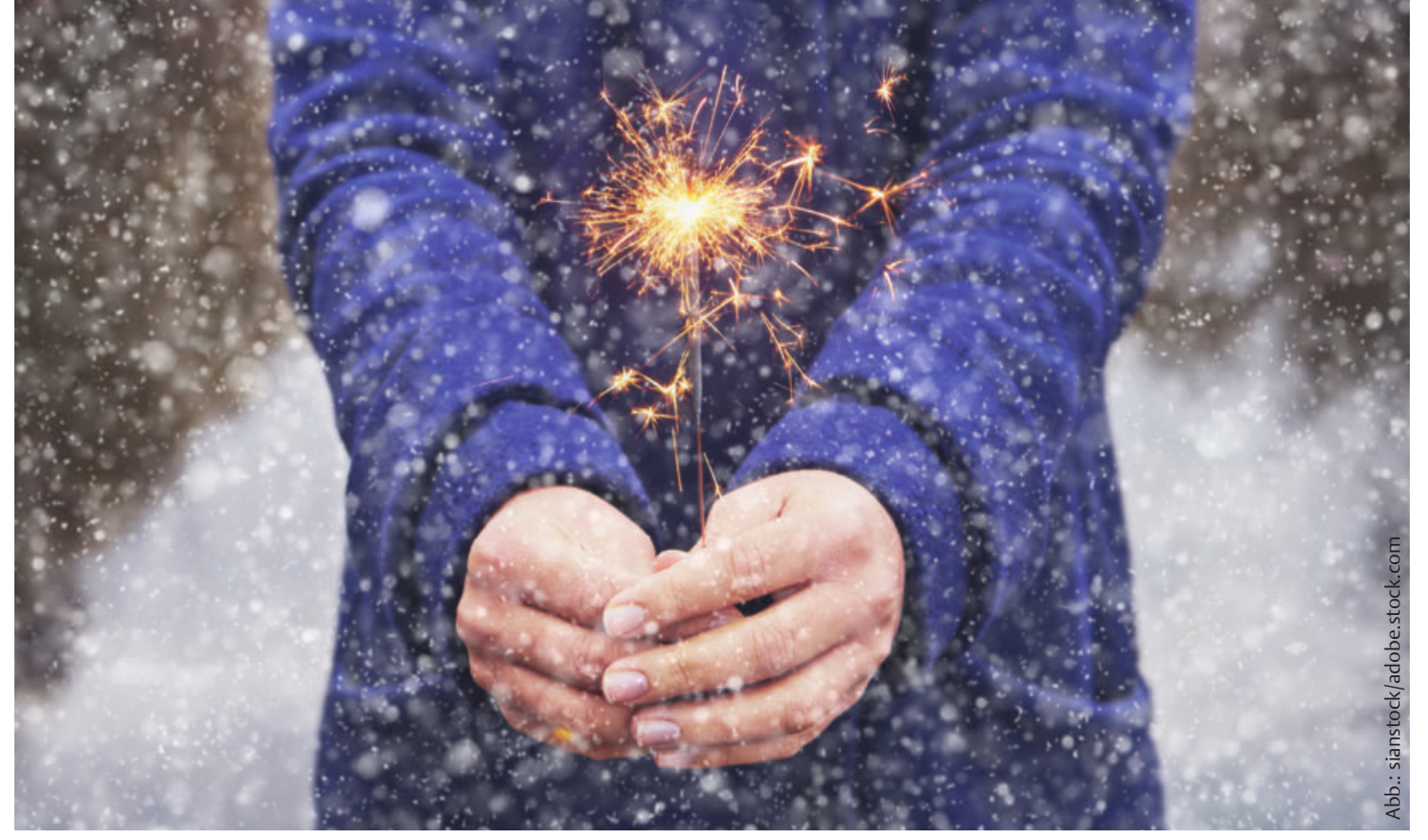

Editorial

\title{
Silvester oder nicht: Ergotherapeuten sind ein Knaller!
}

2018 ist berufspolitisch einiges passiert: Es gibt drei neue Vorstandsmitglieder im Verband Deutscher Ergotherapeuten (DVE), und Bundesgesundheitsminister Jens Spahn lud die Heilmittelerbringer in das Gesundheitsministerium ein. Dabei ging es unter anderem um Direktzugang, Grundlohnsummenbindung, Akademisierung und Schulgeldfreiheit. Innerhalb kürzester Zeit veröffentlichte er ein Eckpunktepapier so schnell hatte niemand damit gerechnet.

$$
\begin{aligned}
& \text { „365 neue Tage und } \\
& \text { damit } 365 \text { neue } \\
& \text { Chancen, Möglich- } \\
& \text { keiten und Taten." }
\end{aligned}
$$

nehmer über die Problematik der Heilmittelerbringer austauschen konnten.

In der psychiatrischen Ergotherapie sind dank neuer Therapiemanuale

Veränderungen zu spüren, und die Überarbeitung der WFOT-Minimumstandards verhilft der Ergotherapieausbildung zu einer Weiterentwicklung. Darüber hinaus tagte die Arbeitsgruppe „deutsche Occupational Science“, und die erste „Deutsche Gesellschaft für Ergotherapiewissenschaft" gründete sich. Ich habe den Eindruck, es passiert etwas - Sie auch?

Ein Neujahrsspruch lautet: 365 neue Tage, 365 neue Chancen, 365 neue Möglichkeiten, 365 neue Taten - ich hoffe, 2019 wird mindestens ebenso aktiv für die Ergotherapie wie 2018. Wir sind schließlich Helden des Alltags oder eben einfach: ein Knaller.

Ihre

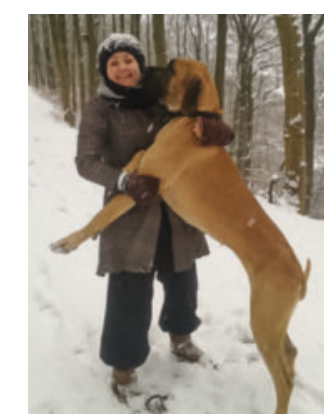

Nicole Kaldewei

Herausgeberin ergopraxis n.kaldewei@gmx.de 